Divyesh Patel, C.S., \& Patel, N.K. (2021). India Gas Exchange Today's Reality and Path Ahead. Copernican Journal of Finance \& Accounting, 10(1), 31-51. http://dx.doi.org/10.12775/CJFA.2021.002

\author{
C.S. Divyesh Patel* \\ C.K. Shah Vijapurwala Institute of Management \\ Dharmsinh Desai University \\ Dr. Naresh K. Patel ${ }^{* *}$ \\ Dharmsinh Desai University
}

\title{
INDIA GAS EXCHANGE TODAY'S REALITY AND PATH AHEAD
}

Keywords: Indian Gas Exchange (IGX), Indian Energy Exchange (IEX), Oil and Gas sector of India.

J E L Classification: Q4, P28, 013.

Abstract: This research aims to study structure, functioning and operational mechanism of India's first gas exchange i.e. Indian Gas Exchange (IGX) which is a subsidiary of Indian Energy Exchange (IEX). Exploratory research is used to study and investigate conceptual framework and operational mechanism of IGX. The results of the study show that IEX has unveiled the nation's first automated natural gas exchange trading platform called IGX for well organized and hefty Gas market and to stimulate gas trading in the country. IGX would lead India towards Gas Based Economy by designing and providing robust solution for natural gas trading and access. So far as price mechanism

Date of submission: November 7, 2020; date of acceptance: January 3, 2021.

* Contact information: csdpatel@gmail.com, C. K. Shah Vijapurwala Institute of Management (CKSVIM), R. V. Desai Road, Nr, Goya Gate Circle, Pratapnagar, Vadodara, Gujarat, India, phone: (+91) 9998685685; ORCID ID: https://orcid.org/0000-00022357-9786.

${ }^{* *}$ Contact information: nareshpatel13@gmail.com, Faculty of Management and Information Sciences, Dharmsinh Desai University, Nadiad, Gujarat, India, phone: (+91) 9426699665; ORCID ID: https://orcid.org/0000-0001-9032-5295. 
at IGX is concerned, it is dynamic and market driven which is based on Double-sided closed auction with uniform price mechanism. IGX plays an extremely important and fundamental role towards capitalizing a free market for gas. Clearing and Settlement system at IGX is structured and transparent. As IGX is purely electronic trading platform for natural gas which is considered as barometer of the India's progressive policy as it integrates the entire energy value chain from gas production.

\section{INTRODUCTION}

India is the home of over 1352.62 million people. There is paradigm shift towards fully developed nation by the middle of this century. Progressing towards fully developed nation, there are two major important factors namely Industrial Revolution and framing of sustainable development goals (Alam, Alam, Reza, Khurshid-ul-Alam, Saleque \& Chowdhury, 2017). India needs secured gas, energy, power generation and distribution and its supply. It has been supplemented in research of Chakraborty (2019) that deteriorating in air quality index and heavy dependence of imported crude oil has stimulated India's energy planning. There has been paradigm shift from traditional sources such as coal, oil, lignite, natural gas, hydro and atomic energy to non-conventional and Renewable Energy resources such as wind power, solar system including waste of rural and household (Ahmad, 2019). Moreover, there is a nexus between economic growth and energy demand; hence, the demand for oil and gas is forecasted to grow more in coming years. The recently established IEX is publicly listed company on both recognized stock exchanges of India namely National Stock Exchange (NSE) and Bombay Stock Exchange (BSE). However, it is administered and controlled by the Central Electricity Regulatory Commission (CERC) with an objective of efficient and transparent price mechanism along with expeditious trade execution of the power market in India. According to LKP Research (2020), IEX has created near monopolistic market with 95\% market share for itself in India's short-term power exchange market. In fact, this market is at a very nascent stage with only around $4 \%$ of India's power produced transacted through exchanges compared to 30\% in developed economies (HDFC sec RESEARCH, 2020). Logistic and Trading mechanism of Gas and Electricity have been almost similar. Hence, having good command on the electricity exchange, IEX is eager to take benefit of its technology platform, expertise and capability. By leveraging its expertise, IEX has launched an IGX. This paper attempts to study and investigate conceptual framework and operational mechanism of IGX. 


\section{INDIAN GAS MARKET SCENARIO}

Natural gas is considered to be the cleanest fossil fuels which can be used as a raw material in the manufacture of fertilizers, other organic chemicals including plastics. In fact, It can also be used as a fuel for electricity generation and heating in industrial units. It is another form of energy which is treated as cleaner form of fuel (ABDI, 2019). It is supported by research of Vikas and Bansal (2019) that Indian oil and gas sector deals with refining, transportation and marketing of these products which approximately contributes $15 \%$ to India's GDP. Oil and gas sector contributes about $34.4 \%$ to primary energy consumption in India. The oil and gas industry has been depicted in figure 1.

Figure 1. Oil and Gas Industry - Major Sectors

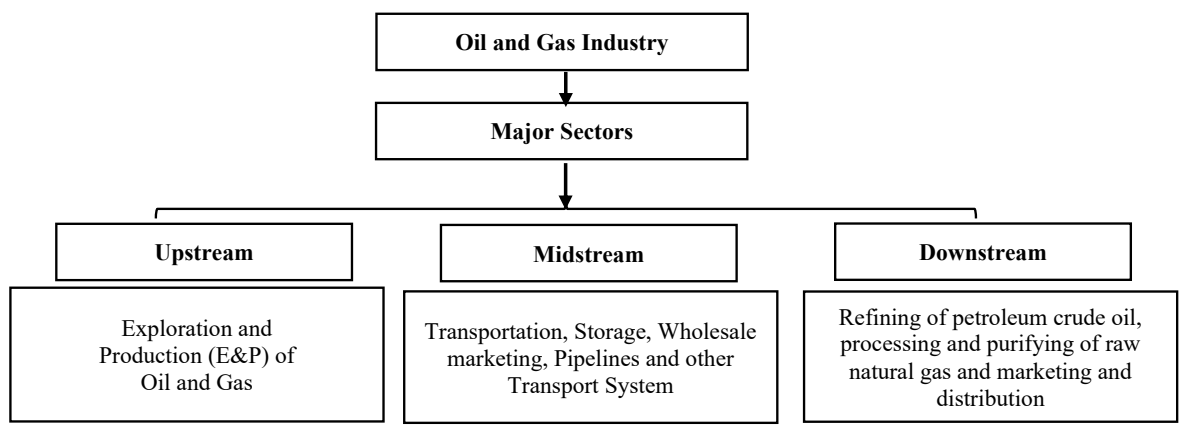

S o u r c e : Soni \& Chatterjee, 2014.

It is inevitable to understand Gas Supply sources in India which is schematically presented in figure 2 as their uses are not only limited to cooking in domestic households but as a transportation fuel for vehicles also. 
Figure 2. Gas Supply sources in India

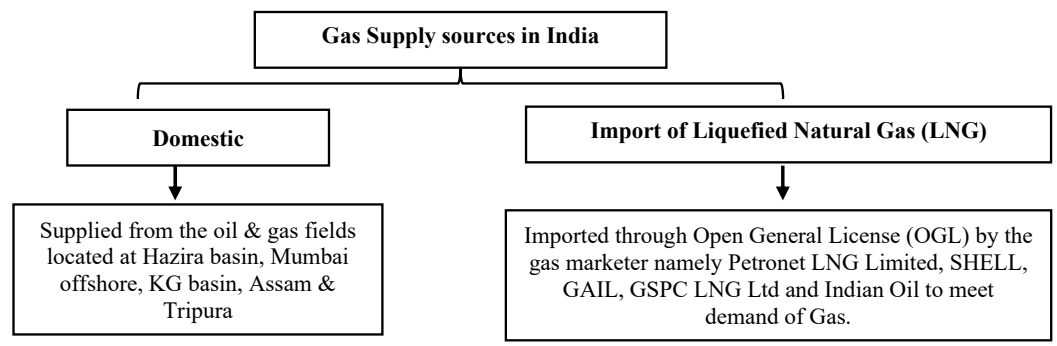

S o u r c e : Gas, 2020.

Due to deteriorating and contraction of productivity in existing sources of natural gas, domestic production of gas has been drastically declining over the past two fiscals. If we throw lights on current Natural gas consumption of India, domestically produced natural gas constitute for less than $50 \%$ of while imported Liquefied Natural Gas accounts for the rest. As per the report of Ministry of Petroleum and Natural Gas (Gas, 2020) regarding consumption of gas per day would be about 165 million cubic meters out of which approximately $47 \%$ would be met by import of liquefied natural gas which is depicted in figure 3. Natural Gas Consumption is getting increase gradually (13\% Appx.) since from Financial Year (FY) 2014 to 2019 where 47\% approximately constituted LNG imports.

Figure 3. Gas Consumption (India)

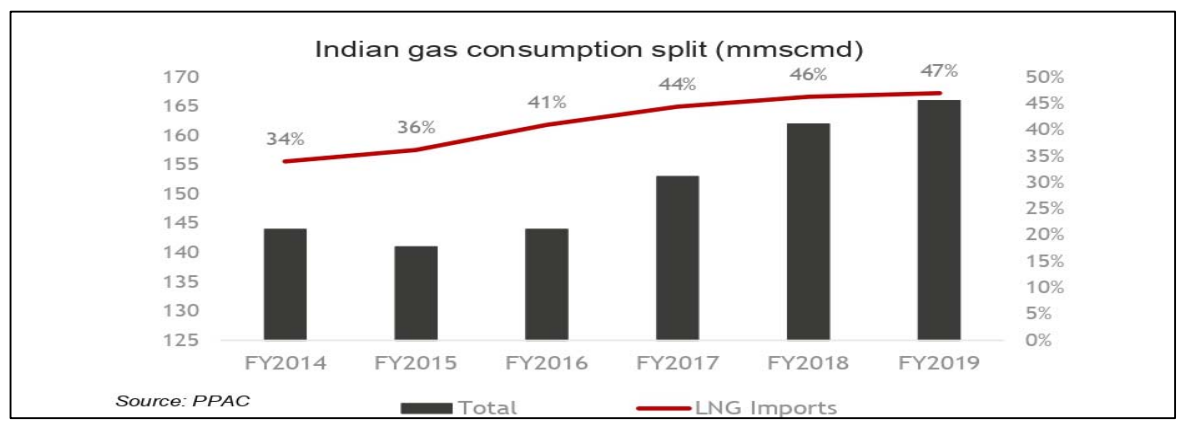

S o u r c e : Petroleum Planning \& Analysis Cell (PPAC) India. 
It can be inferred from figure 4 that India is gradually increasing its LNG imports almost 10\% during last 6 years (i.e., FY 2013 to 2018) and ultimately fiscal burden lies on Government of India.

Figure 4. Trend of Import of Liquefied Natural Gas (India)

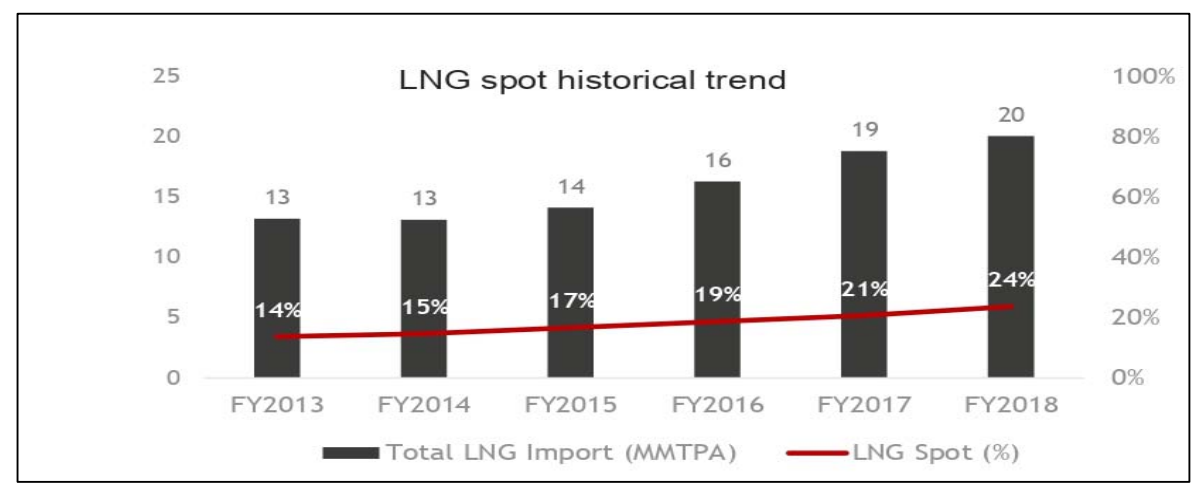

S o u r c e : CRIS Analysis.

It is imperative to develop diverse market place for Oil and Gas sector in India because of two fundamental aspects namely strong consumer base (in terms of consumers in domestic, commercial or industrial and transport sectors) and price sensitivity. Generally, of the total gas demand of country in 2019, household and transport which is approximately $66 \%$ which has been taken care of by power industries in association with City Gas Distribution networks. However, around $50 \%$ of the same has been met with low priced domestic gas (IEA, 2021). It can be inferred from figure 5 that natural gas consumption by Power, Fertilizers and City Gas Distribution (CGD) are most sensitive as compared to other sectors. 
Figure 5. Natural Gas Consumption (India)

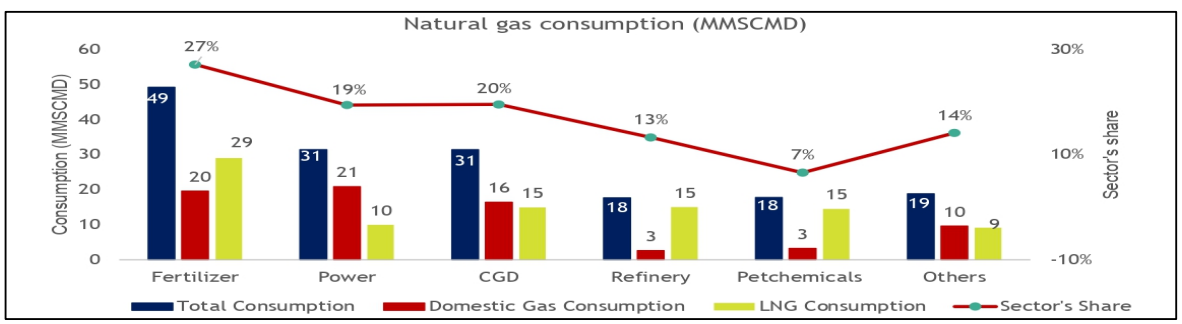

S o u r c e : CRIS Analysis.

Such optimistic trends would influence gas market supplies significantly and in line with Ministry of Petroleum and Natural Gas is also taking progressive steps towards increasing share of gas in Indian Energy Mix to 15\% (which is around 6.2\% currently) to make India a Gas Based Economy (The Economic Times, 2020).

As per report of India (2020) the Indian gas market constitutes around 166 mmscmd and is expected to reach around $600 \mathrm{mmscmd}$ in coming decade. It means there will be approximately $261 \%$ contribution expected over span of 7 to 10 years. Many Countries are adopting gas as a primary energy source for the sake of air quality and carbon emission benefits. Now, more state has officially prohibited fuel oil as industrial consumers are the largest gas consuming segment. It is supported by Global Gas Report 2019 and came out with research that Gujarat's ceramic industry has drastically reduced air pollution and environmental contamination due to shifting from coal usage to natural gas after March 2019 and credit goes to smooth gas distribution networks. It has been stated that PM2.5, PM10 and S02 concentration have been reduced by 75\%, 72\% and 85\% respectively by August 2019 as compared to 2017 (International Gas Union, 2020). IEX has recently unveiled Indian Gas Exchange (a wholly owned subsidiary) to facilitate smooth and expeditious gas trading in India.

\section{The Research Methodology and the Course of the Research Process}

The research is purely based on secondary data pertaining to Indian Gas Exchange. The source of data collection for the study was obtained through the 
web sources of Indian Gas Exchange Ltd. This study used market data of IGX products based on Buy Bid and Sell Bid for the period for the period from June2020 to October-2020 as a sample period of four main Gas Exchange Hubs namely Dahej, Hazira, Odoru and KG Basin. Exploratory study is carried out during stages of research process to narrow the scope of research objectives and to transform ambiguous problems into well-defined one. The technique to study exploratory research is secondary market analysis. Descriptive research (a part of Conclusive research) is also used to help in providing specific information so as to evaluate the conceptual framework and operational mechanism of IGX. IGX market model with reference to contractual framework/ Arrangement has been presented in chart 1 .

Chart 1. IGX Market Model

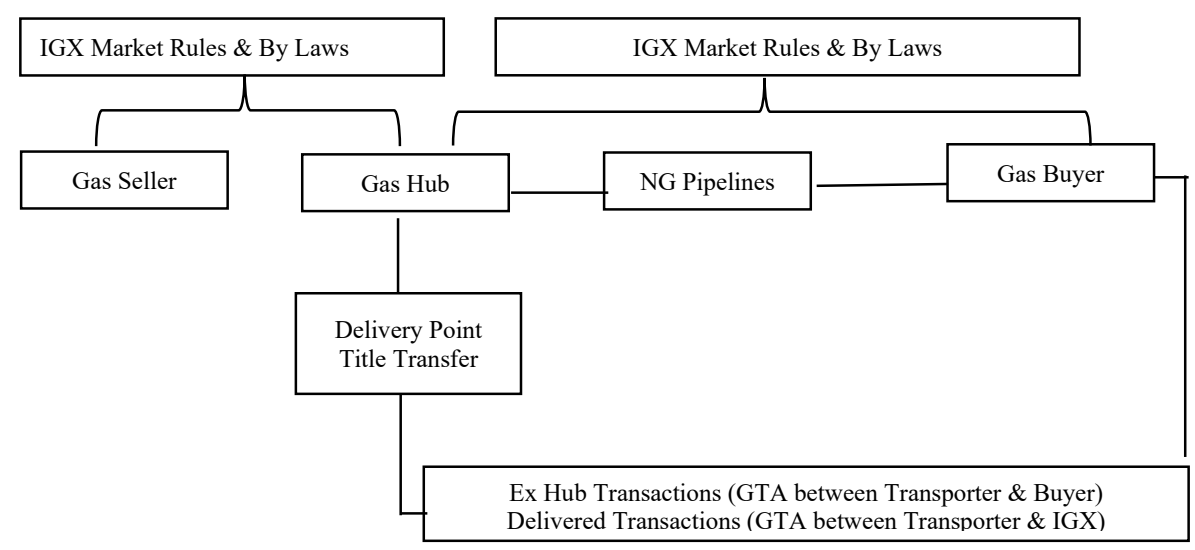

S o u r c e : Exchange, 2020 \& compiled by researcher.

INDIAN GAS EXCHANGE- OPERATIONAL MECHANISM

\section{Introduction}

The Government of India has framed a progressive policy in the field of Indian Energy Segment that to increase share of natural gas to $15 \%$ by 2030 as compared to current share of $6.5 \%$. If we look at from global perspective, the share of gas in energy mix is about $23.5 \%$ currently. So in order to increase share of 
natural gas in India, it is indispensible to have healthy investments in Gas Economy infrastructure in terms of value chain, regasification (i.e. Conversion of LNG to natural gas), pipeline transportations etc. India's first nationwide gas exchange IGX was launched on 15 June 2020 with an objective of moving towards laissez-faire gas prices and to give an edge to the investment in gas infrastructure in India. According to ETEnergyWorld (2020) Now India is in the race of progressive economies as India has achieved a big milestone in the natural gas industry and crafted a new chapter in the energy history of India. Hence, it would provide the nation paradigm shift towards free market pricing of natural gas. The IGX has already 350 registered clients and 12 members (Big New Network, 2020) which provides neutral, transparent and smooth mechanism of Gas trading as the underlying commodity. The price of domestically produced natural gas is in the hands of the government. However, domestically produced natural gas can't be available for trading on the exchange. A Government is in process of giving green signal for trading certain volume of domestic gas on Gas Exchange (Karunjit, 2020).

\section{Digital Trading Platform (Web-Based interface)}

IGX is India's first digital national trading platform automated with web based interface to encourage and uphold an efficient \& hefty Gas market trading in the country. The platform which provides trading facility in spot and forward contracts with numerous buyers and sellers. It has its designated physical hubs namely Dahej and Hazira in Gujarat, and Kakinada in Andhra Pradesh. IGX is web based platform that provides neutral, transparent and smooth mechanism of Gas trading as the underlying commodity. Here, regasification has been carried out (i.e. Conversion of LNG to natural gas) and sold to buyers through this platform. Hence, it eliminates the requirement of buyers and sellers to find each other and would lead to anonymous bidding. Hence buyer need not contact multiple dealers for ensuring the fair price. It allows buyers and sellers greater flexibility. India's spot import is around $25 \%$ of total gas requirement out of total import of 55\%. 


\section{IGX Products}

IGX has wide range of products day ahead (not available for Trade), daily, weekly, weekday, fortnightly and monthly at physical hubs at Dahej and Hazira in Gujarat, Odoru in Andhra Pradesh and Krishna Godavari Basin (KG Basin). Products specification and features would be depicted in table 1. Transactions of these products would be taken place either Ex-hub \& Delivered Contracts subject to margin requirements as per Market rule. In case of ex hub contracts, Exchange will forward details to buyers to dispatch nomination to transporter. While in case of Delivered Contracts, where IGX shall facilitate the trade, physical delivery of Gas by booking the necessary transmission facility, and financial settlement for the traded Contracts.

Table1. IGX Products specifications and features

\begin{tabular}{|c|c|c|c|c|c|c|}
\hline \multirow{2}{*}{ Features } & \multicolumn{6}{|c|}{ Products } \\
\hline & Day Ahead & Daily & Week Day & Weekly & Fortnightly & Monthly \\
\hline $\begin{array}{l}\text { Trading of } \\
\text { contracts for } \\
\text { delivery }\end{array}$ & $\begin{array}{l}\text { D+1 } \\
\text { (i.e., Next gas } \\
\text { day) }\end{array}$ & $\begin{array}{l}\mathrm{T}+2 \text { day } \\
\text { (i.e., } \mathrm{T} \text { is the } \\
\text { trade day and } \\
2 \text { is the delive- } \\
\text { ry day }\end{array}$ & $\begin{array}{l}\text { Monday to } \\
\text { Friday fixed } \\
\text { for } 5 \text { days. }\end{array}$ & $\begin{array}{l}7 \text { days typi- } \\
\text { cally Monday- } \\
\text {-Sunday and } \\
\text { other com- } \\
\text { binations of } \\
7 \text { days }\end{array}$ & $\begin{array}{l}15 / 16 \text { days } \\
\text { each for } \\
\text { a month. } \\
\text { (i.e., } 1 \text { st }-15 \text { th } \\
\text { and } 16 \text { th - } \\
\text { End of Month) }\end{array}$ & $\begin{array}{l}\text { Entire calen- } \\
\text { dar month }\end{array}$ \\
\hline $\begin{array}{l}\text { Availability } \\
\text { of Trading } \\
\text { Window }\end{array}$ & $\begin{array}{l}\text { 1-day prior for } \\
\text { trading on day } \\
\text { ahead basis }\end{array}$ & $\begin{array}{l}\text { Available for } \\
\text { trading up to } \\
\text { a period speci- } \\
\text { fied by IGX }\end{array}$ & $\begin{array}{l}5 \text { days before } \\
\text { the start of } \\
\text { delivery }\end{array}$ & $\begin{array}{l}5 \text { days before } \\
\text { the start of } \\
\text { delivery }\end{array}$ & $\begin{array}{l}5 \text { days before } \\
\text { the start of } \\
\text { delivery for } \\
\text { both the } \\
\text { contracts. }\end{array}$ & $\begin{array}{l}6 \text { days before } \\
\text { the start of } \\
\text { the delivery. }\end{array}$ \\
\hline
\end{tabular}

S o u r c e : adapted from IGX, compiled by researcher.

Contract Specification at IGX would be shown in table 2 (Refer Annexure). Market Data of all IGX Products (except Day Ahead contract as they not available for trade), based on Buy Bid and Sell Bid Qty has been presented in table 3 (Refer Annexure) and schematically presented in figure 6 and Month wise data in figure 7 (Refer table 4 in Annexure). 
Figure 6. Market Data of IGX Products based on Buy Bid and Sell Bid at Dahej, Hazira, Odoru and Krishna Godavari Basin (KG Basin)

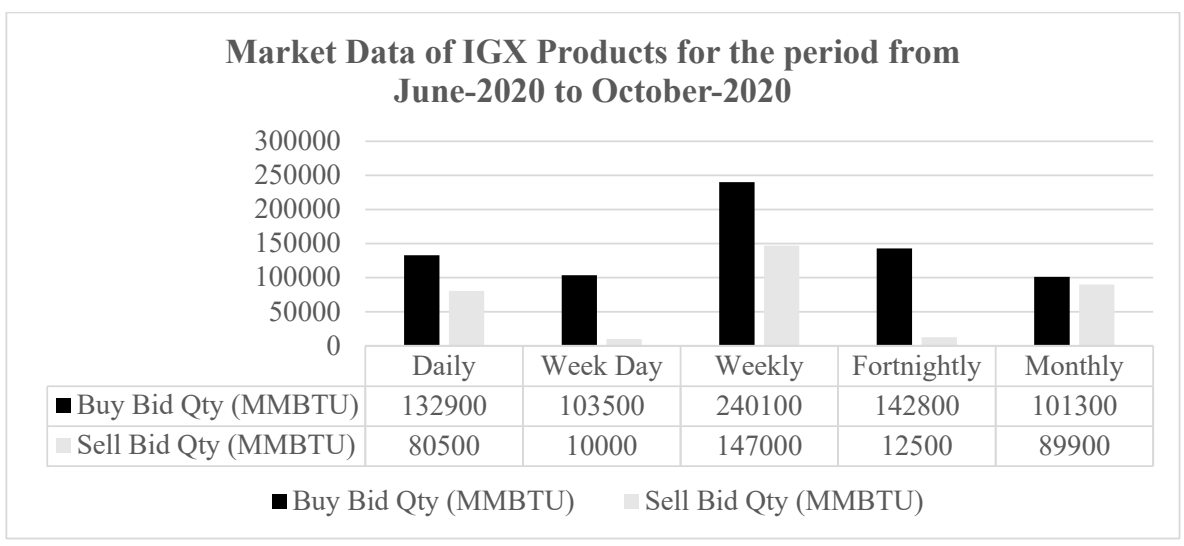

S o u r c e : adapted from IGX data, Derived by researcher IGX.

Figure 7. Month wise Market Data of IGX Products Buy and sell Bid Qty of hubs at Dahej, Hazira, Odoru and Krishna Godavari Basin (KG Basin)

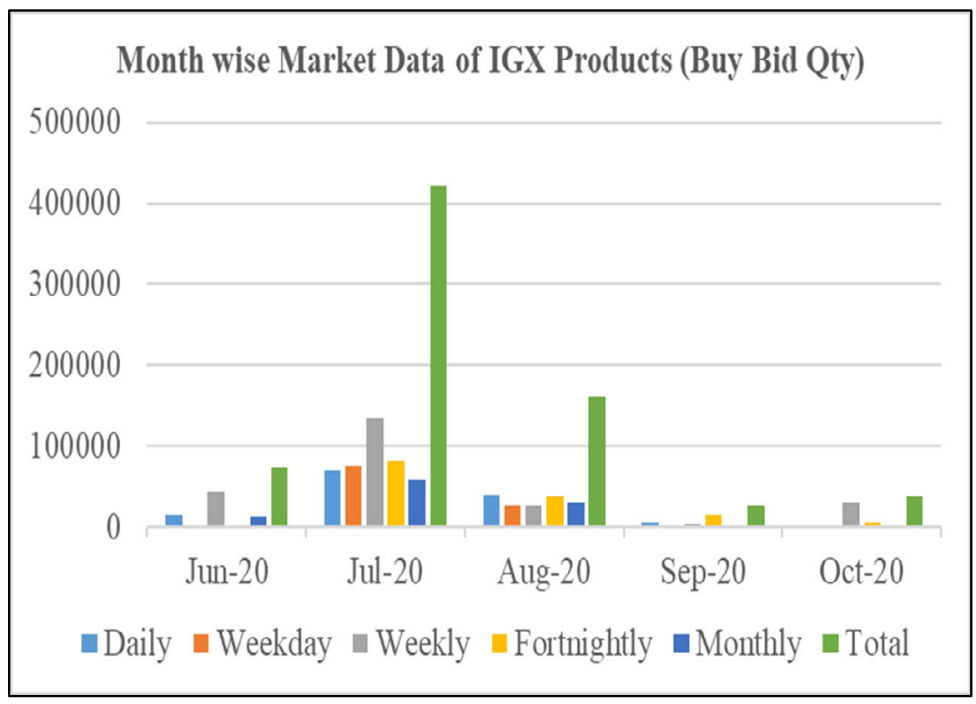




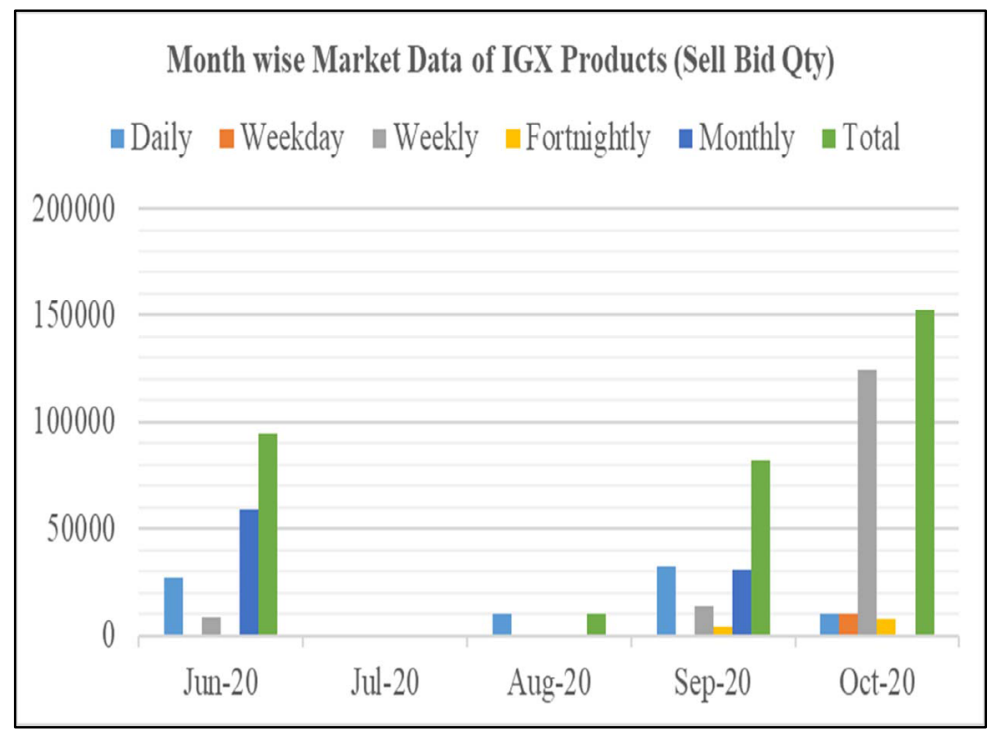

S o u r c e : adapted from IGX data, Derived by researcher IGX.

From figure 6 and 7, it can be inferred that IGX products are gaining momentum gradually. It's an indication of constructive and imperative effects which creates public trust in financial operations leading towards stakeholder's value enhancement and serving to nation's interest. It would reach its peak level as the aim is moving towards laissez-faire gas prices and to give an edge to the investment in gas infrastructure in India by increasing share of natural gas in its energy mix to 15 percent by 2030 (Bhutra, 2020).

\section{Trading Process}

IGX shall conduct transactions as per the terms of Contracts set out under Market Rules. All Orders made by the Members shall be sent via electronic interface to the Gas Trading Platform for matching process and execution. In case of any contingency at the Member's end, IGX has the right to accept or not accept to place/modify/cancel the order request received from the Member. Order matching rules ensure that Orders are executed based on the prices available in IGX trading system and will be as per algorithms set. Auction trade session: 10:00 to 12:00 as per trading calendar. Prior to placing the Orders, the Buyers and Sellers shall post with the IGX such amount as margin, as may be required 
by them in advance in order to trade for Contracts as specified by IGX from time to time and as set out under the Contracts ("Margin"). Such margins may be in cash and non-cash form as specified by IGX. The cash Margins are to be deposited to the Settlement Account and shall be used for completion of payments for a transaction as per the terms of the Contracts. The amounts in the Settlement Account are to be replenished up to the relevant Margin requirements before placing of an Order by a Member.

\section{Figure 8. Trading Process at IGX}

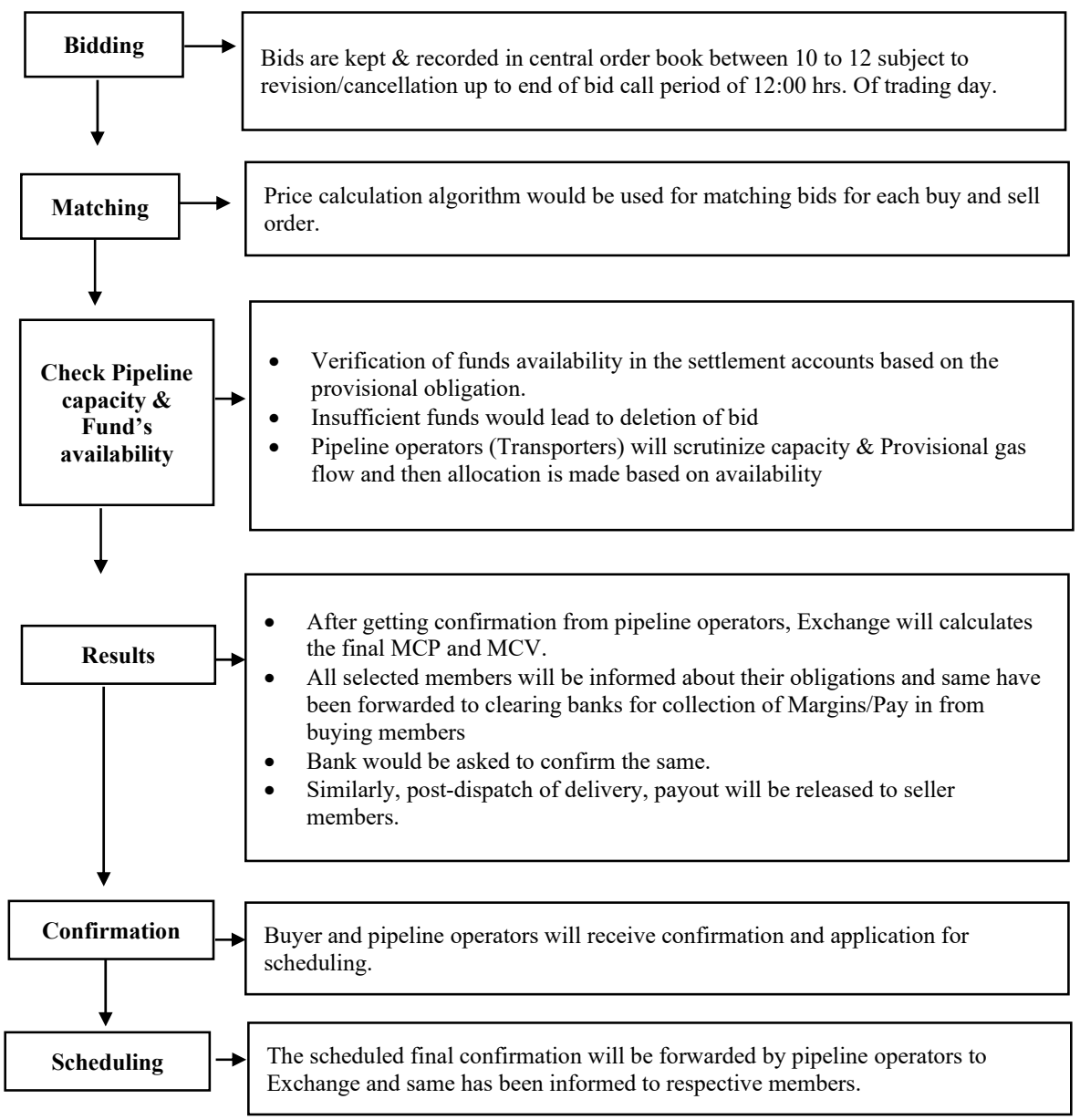


The entire trading process starting from Bidding to Scheduling has been depicted in figure 8. Generally, Bid Call Session starts from 10:00 - 12:00 hrs where Members has right to submit and edit bids. However, they can modify or delete the bids also. Around 12:45 hrs., Results would be published where IGX calculates the final Market Clearing Price (MCP) and Market Clearing Volume (MCV). Transactions whether Ex hub or Delivered Transactions to be taken place around 16:00 hrs. The scheduled final confirmation will be forwarded by pipeline operators to Exchange and same has been informed to respective members at closing of trade on 18:00 hrs.

\section{PRICE DISCOVERY}

Powell (2020) stated that India is a price sensitive country where Price distortion is one of the severe hindrances to become gas-based economy and hence it disheartens the investment in market forces (i.e. supply and demand). The similar view has been found in the research of Mahapatra and Dholakia (2014) that pricing mechanism is full of irregularities so far as natural gas sector in India is concerned the reason being scarcity of suppliers with highly complex or intricate contracts and ultimately it turns out to be in welfare losses, and market failure. Here IGX will play in a pivotal role in ensuring and computing gas prices. Hence, the IGX has framed well-organized and market-based gas price discovery which facilitates smaller companies to source gas competitively and fertilizers, power, and city gas distribution sectors as they are the key consumers of gas. Singh, Shukla and Dhar (2009) have observed in their study that the benefits are responsive to global gas prices as higher gas prices would lead to curb the demand for gas. The price will be determined by two ways. First using Uniform Price double-sided Closed Auction and secondly by Continuous trade mechanisms (Gas, 2020). In case of first discovery price mechanism, the participants will enter their bids to buy or sell at a specific price point and one single uniform market clearing price would be decided by market.

A Matching of the Uniform Price double-sided mechanism will be applicable only in the circumstances where buying price is more than equal to selling price (i.e. Bid Price is more than equal to Ask price) in order book. Where in case of Continuous trade, the price will be coordinated continuously based on bids and offers. Orders are coordinated and prioritized based on price and time. It means Best buying order is corresponded with best selling order. How- 
ever for order matching is concerned, best buying order refers to highest price and best selling order implies lowest price.

\section{Clearing \& Settlement Mechanism}

Clearing is the process of updating accounts of trading parties and making arrangements for transfer of money and underlying asset (Gas). While Settlement deals with actual exchange of money and underlying asset (Gas) between parties of trade on settlement date. (i.e. Delivery of underlying asset (Gas) and "Fund Pay in" or "Fund Pay out" process would be completed).

Details related to financial and delivery-based Obligations would be provided to participants periodically and same has to be settled as per the settlement calendar of exchange. The availability of contract and their active hubs would be located and easily identified to make the process smoother. Settlement passes through various procedures which have been summarized in figure 9 .

Figure 9. Clearing and Settlement procedure at IGX

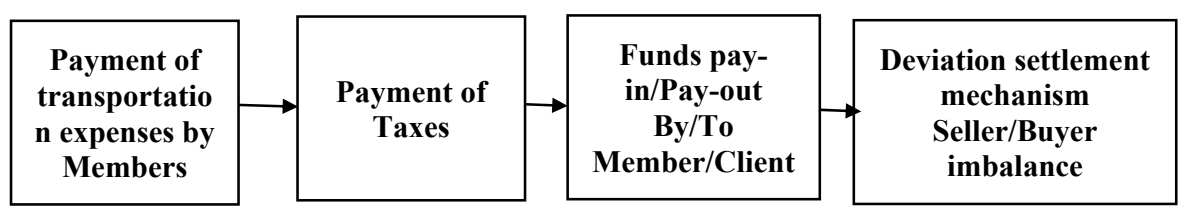

S o u r c e : adapted from IGX data, Derived by researcher IGX.

Transportation expenses on Scheduled Quantity at the Entry point will be settled by the members with the IGX separately as per the trading calendar as declared by the IGX and subsequently will be paid to the Transporter by the IGX in case of delivered transactions while in case of Ex-hub transactions, it will be paid by the Members to the Transporter directly. During process, IGX (A facilitator) will collect the taxes on commodity from Buyers and pay it to Seller. Seller will generate the invoice in name of Buyer with a copy market to IGX and once the Seller issues the invoice, IGX will release the tax to Seller. At last, IGX will debit the funds pay-in and Credit funds pay-out according to trading and settlement calendar.If seller injects less quantity than the final allocated, then 
funds will be adjusted from Seller's Settlement Account as per Deviation settlement mechanism.

\section{LEGAL FRAMEWORK}

Regulatory advocacy of IGX basically depends on Market Rules of Gas Trading Platform and according to the provisions of the Petroleum and Natural Gas Regulatory Board Act 2006 along with Central Government rules, regulations, codes, notifications and circulars.Market Rules have framed the guidelines for operation of the GTP for trade and enhancing competitiveness with high level of efficiency. In nut shell, IGX governance structure includes IGX Bye-laws, Circulars, Market Rules including Contract Specifications which deals with rules regarding how to execute trade at exchange and its trading forms including standard lot size, order types and its execution.

\section{IMPLICATIONS AND LIMITATIONS}

There are hurdles still to overcome like pricing of domestic gas, Gas Grid including Gas pipeline infrastructure and taxation aspects of gas. The price of domestically produced natural gas is in the hands of the government. However, domestically produced natural gas can't be available for trading on the exchange. The initial days of trading result stated that price of $\$ 4.07 / \mathrm{MMBtu}$ for imported gas which is an indication of under pricing of domestic gas (Shine, 2020). Under-pricing of domestic gas would discourage domestic production toward corresponding demand. Price distortion is one of the severe hindrances to become gas-based economy and hence it disheartens the investment in market forces (i.e. supply and demand). If we look at from pipeline infrastructure point of view which is indispensible for transportation of natural gas, has been controlled by organizations that have their own network. In India, Gas Authority of India Ltd (under ownership of Ministry of Petroleum and Natural Gas , Government of India) owns and operates India's biggest gas pipeline network approximately more than $12,000 \mathrm{~km}$. Moreover, transportation of gas in the country by means of pipelines is the most economical way. Currently in India, around $16,788 \mathrm{~km}$ gas pipeline network is under process and around $14,500 \mathrm{~km}$ pipeline has been approved for under construction. One more limitation and challenge in front of industries is in terms of taxation. As gas is still 
not covered under Goods and Service Tax and hence it would raise question for claiming an input tax credit on inputs availed by industries. Hence, Government is under the process of covering natural gas under Goods and Service Tax regime for uniform taxation.

The shifting of total volume on gas exchange hubs will decide the success of IGX. The Government is putting its continuous efforts to wrap up the Gas Grid in time horizon. In fact,

Petroleum and Natural Gas Regulatory Board has expedited its bidding process of the pipelines for missing sections to finish grid work (Pathak, 2020). It provides constructive and imperative effects which creates public trust in financial operations leading towards stakeholder's value enhancement and serving to nation's interest.

\section{FUTURE SCOPE}

As per the report of Industry Group for Petroleum \& Natural Gas Regulatory Board (2013) regarding natural gas demand, it has been researched that gas demand is to rise notably at Compound Annual Growth Rate of about $6.8 \%$ that is 242.6 MMSCMD in 2012-13 to 746 MMSCMD in 2029-30 which reflects realistic demand of natural gas in India. The report has also highlighted about expected contribution of gas based power generation in between $36 \%$ to $47 \%$ in the projected period of 2012-13 to 2029-30. So far as total supply of natural gas is concerned, it is expected to grow at Compound Annual Growth Rate of about 7\% over span of 18 years (i.e. from 2012-2030) and in terms of Million Metric Standard Cubic Meter Per Day (MMSCMD), it would reach to 400 and expected to reach around 470 by 2029-30. IGX in its way forward to expand its segments by establishing new hubs and launching of new products like Liquefied natural gas, furnace oil, Low Sulphur Heavy Stock. IGX is looking forward futuristic technology Infrastructure for customers and enhancements to the trading platform with the help of PNGRB and Ministry of Petroleum and Natural Gas. In short span, IGX provides value to the customers and serves the nations interest by increased investments in Exploration and Production sector, optimal utilization of infrastructure, revival of gas-based power plants as IGX provides competitive rates for grid balancing purpose in upcoming high Renewable Energy scenario (Exchange, 2020). Dziawgo investigated in his research and focused on "greening" financial market which supports proecological transfor- 
mation of the society and economy (Dziawgo, 2014). The process is powerful and fast where renewable energy sector is going to become driving force of change. Moreover, with the help of competitive pricing mechanism of IGX, it is possible for fertilizer industry to reduce their prices and subsidy burden on Government of India. Emergence of a trading platform for natural gas not only enables vibrant trading in natural gas, but also provides benchmarks after inculcating the information on local demand and supply, for pricing various gas transactions in a more efficient and transparent manner.

\section{CONCLUSION}

IGX would lead India towards Gas Based Economy by designing and providing robust solution for natural gas trading and access. India's leading electricity trading exchange (IEX) has unveiled the nation's first natural gas exchange called IGX on 15 June 2020 with an objective of moving towards laissez-faire gas prices and to give an edge to the investment in gas infrastructure in India. IGX is India's first digital national trading platform automated with web based interface to encourage and uphold an efficient \& hefty Gas market trading in the country with structured legal framework of PNGRB Act, rules and Bye Laws. IGX in its way forward to expand coverage and market by adding new hubs and launching of new products. IGX is fondly anticipates and made diligent efforts in technology Infrastructure investments focusing on technology \& analytics driven solutions for customers to enhance to the trading platform functions. Exchange is more focusing on development of ecosystem emphasizing policy and regulatory advocacy. There are hurdles still to overcome like pricing of domestic gas, Gas Grid including Gas pipeline infrastructure and taxation aspects of gas. In short span, IGX provides value to the customers and serves the nations interest by increased investments in Exploration and Production sector, optimal utilization of infrastructure, revival of gas-based power plants as IGX provides competitive rates for grid balancing purpose in upcoming high Renewable Energy scenario. 


\section{REFERENCES}

ABDI, E.J. (2019). Seasonal analyses of solar radiation on flat ground for different stat of sky: Case of Nouakchott, Mauritania. International Journal of Physical Sciences, 14(12), 125-138. http://dx.doi.org/10.5897/IJPS2019.4830.

Ahmad, F. (2019). Assessment of power exchange-based electricity market in India. Energy Strategy Reviews, 23, 163-177. http://dx.doi.org/10.1016/j.esr.2018.12.012.

Alam, F., Alam, Q., Reza, S., Khurshid-ul-Alam, S.M., Saleque, K., \& Chowdhury, H. (2017). Regional power trading and energy exchange platforms. Energy Procedia, 110, 592596. http://dx.doi.org/10.1016/j.egypro.2017.03.190.

Bhutra, S. (2020). India's first gas exchange launched: What it means for the gas economy and companies, https://www.cnbctv18.com/market/indias-first-gas-exchangelaunched-what-it-means-for-the-gas-economy-and-companies-6145721.htm (accessed: 03.01.2021).

Big New Network (2020). IEX launches India's first gas trading platform, https://www. bignewsnetwork.com/news/265455857/iex-launches-india-first-gas-trading-platform (accessed: 03.01.2021).

Chakraborty, R.K. (2019). First natural gas exchange to be unveiled by March, https:// economictimes.indiatimes.com/markets/commodities/news/first-natural-gas-exchange-to-be-unveiled-by-march/articleshow/72255425.cms (accessed: 03.01.2021).

Dziawgo, L. (2014). Greening financial market. Copernican Journal of Finance \& Accounting, 3(2), 9-23. http://dx.doi.org/10.12775/CJFA.2014.014.

ETEnergyWorld (2020). The Economic Times. Gas exchange opens a new chapter in India's energy history, https://energy.economictimes.indiatimes.com/news/oil-andgas/gas-exchange-opens-a-new-chapter-in-indias-energy-history-new-tariff-policy-soon-pradhan/76383082 (accessed: 03.01.2021).

Exchange, I.G. (2020). Welcomes you to the launch of India's first online gas trading platform, https://www.igxindia.com/wp-content/uploads/2020/06/IGX-LaunchPresentation.pdf (accessed: 03.01.2021).

Gas, M.O. (2020). Ministry of Petroleum and Natural Gas, https://petroleum.nic.in/natural-gas/about-natural-gas (accessed: 03.01.2021).

HDFC sec RESEARCH (2020). Indian Energy Exchange Ltd. Retail research, https://www. hdfcsec.com/hsl.research.pdf/IEX\%20Ltd-\%20Initiating\%20Coverage-29062020.pdf (accessed: 03.01.2021).

IEA (2021). India Energy Outlook 2021, IEA, Paris, https://www.iea.org/reports/indiaenergy-outlook-2021 (accessed: 03.01.2021).

India, B.I. (2020). Gas grid to be expanded to $27,000 \mathrm{~km}$, pricing reforms in offing, https:// www.businessinsider.in/business/news/gas-grid-to-be-expanded-to-27000-km-pricing-reforms-in-offing/articleshow/73850068.cms (accessed: 03.01.2021).

Industry Group for Petroleum \& Natural Gas Regulatory Board (2013). Vision 2030: Natural Gas Infrastructure in India. New Delhi, India: Petroleum \& Natural Gas Regulatory Board (accessed: 03.01.2021). 
Karunjit, S. (2020). India's first gas exchange: what it is, and how it will work, https://indianexpress.com/article/explained/indian-gas-exchange-igx-what-it-is-and-howit-will-work-6460379 (accessed: 03.01.2021).

LKP Research (2020). Indian Energy Exchange: Facilitating Growth in the Power Market, https://www.lkpsec.com/Admin/Research/637307019707970605_IEX_IC_ LKP_JULY20.pdf (accessed: 03.01.2021).

Mahapatra, D., \& Dholakia, R.H. (2014). Natural Gas Pricing in India. Gujarat: Indian Institute of Management Ahmedabad.

Pathak, K. (2020). Mint: India launches maiden gas exchange, https://www.livemint. com/industry/energy/india-launches-maiden-gas-exchange-11592209492756.html (accessed: 03.01.2021).

Powell, L. (2020). India Natural Gas Exchange - one small step or a giant leap? https://www. orfonline.org/research/india-natural-gas-exchange-one-small-step-or-a-giant-leap (accessed: 03.01.2021).

Shine, J. (2020). GAIL, Adani, Petronet LNG join IGX; gas price of $\$ 4.07$ per unit discovered, https://www.business-standard.com/article/companies/gail-adani-petronet-lng-join-igxgas-price-of-4-07-per-unit-discovered-120061800043_1.html (accessed: 18.06.2020).

Singh, A., Shukla, P. R., \& Dhar, S. (2009). Regional cooperation towards trans-country natural gas market. International Journal of Energy Sector Management, 3(3), 251-274. http://dx.doi.org/10.1108/17506220910986798.

Soni, A., \& Chatterjee, A. (2014). Governance of the Petroleum and Natural Gas Sector in India: A Status Note. The Energy and Resources Institute TERI-NFA Working Paper Series, 15.

The Economic Times (2020). Dharmendra Pradhan says pipeline tariff rationalization, gas pricing freedom on anvil, https://economictimes.indiatimes.com/industry/energy/oil-gas/dharmendra-pradhan-says-pipeline-tariff-rationalisation-gas-pricingfreedom-on-anvil/articleshow/76734097.cms?from=mdr (accessed: 03.01.2021).

Vikas, V., \& Bansal, R. (2019). Efficiency evaluation of Indian oil and gas sector: data envelopment analysis. International Journal of Emerging Markets, 14(2), 362-378. http://dx.doi.org/10.1108/IJoEM-01-2018-0016. 


\section{ANNEXURE:}

Table 2. Contract Specification at IGX

\begin{tabular}{|l|l|}
\hline \hline Segment & Physical delivery \\
\hline Contract Volume & Lot size Basis \\
\hline Contract Volume Unit & MMBTU Per Day \\
\hline Lot Size & $\begin{array}{l}1 \text { Lot = 100 MMBTU } \\
\text { NMB } \\
\text { natural gas in the energy terms globally }\end{array}$ \\
\hline Price Unit & INR/MMBTU \\
\hline Delivery Type & Ex-Hub and Delivered transactions \\
\hline Margin Rate & As per Market Rules \\
\hline Hub & Dahej, Hazira, Odoru and KG Basin \\
\hline \hline
\end{tabular}

S o u r c e : adapted from IGX Market Rules (Volume II), compiled by researcher.

Table 3. Market Data of IGX Products based on Buy Bid and Sell Bid Qty for the period from June-2020 to October-2020 of hubs at Dahej, Hazira, Odoru and KG Basin

\begin{tabular}{|l|c|c|}
\hline \hline \multicolumn{1}{|c|}{ Product } & Buy Bid Qty (MMBTU) & Sell Bid Qty (MMBTU*) \\
\hline \hline Daily & $\mathbf{1 3 2 9 0 0}$ & $\mathbf{8 0 5 0 0}$ \\
\hline Week Day & 103500 & 10000 \\
\hline Weekly & 240100 & 147000 \\
\hline Fortnightly & 142800 & 12500 \\
\hline Monthly & 101300 & 89900 \\
\hline \hline
\end{tabular}

S o u r c e : adapted from IGX, compiled by researcher. 
Table 4. Month wise Market Data of IGX Products Buy Bid Qty (MMBTU) of hubs at Dahej, Hazira, Odoru and KG Basin

\begin{tabular}{|l|c|c|c|c|c|c|}
\hline \hline \multicolumn{1}{|c|}{ Month } & Daily & Weekday & Weekly & Fortnightly & Monthly & Total \\
\hline \hline Jun-20 & 16100 & - & 44100 & 1500 & 12400 & 74100 \\
\hline Jul-20 & 69700 & 76000 & 135100 & 82000 & 58900 & 421700 \\
\hline Aug-20 & 39500 & 26000 & 27300 & 37900 & 30000 & 160700 \\
\hline Sep-20 & 6300 & 1500 & 3500 & 15000 & - & 26300 \\
\hline Oct-20 & 1300 & - & 30100 & 6400 & - & 37800 \\
\hline \hline
\end{tabular}

S o u r c e : adapted from IGX, compiled by researcher.

Table 5. Month wise Market Data of IGX Products Sell Bid Qty (MMBTU) of hubs at Dahej, Hazira, Odoru and KG Basin

\begin{tabular}{|l|c|c|c|c|c|c|}
\hline \hline \multicolumn{1}{|c|}{ Month } & Daily & Weekday & Weekly & Fortnightly & Monthly & Total \\
\hline \hline Jun-20 & 27600 & - & 8400 & - & 58900 & 94900 \\
\hline Jul-20 & - & - & - & - & - & 0 \\
\hline Aug-20 & 10400 & - & - & - & - & 10400 \\
\hline Sep-20 & 32500 & - & 14000 & 4500 & 31000 & 82000 \\
\hline Oct-20 & 10000 & 10000 & 124600 & 8000 & - & 152600 \\
\hline \hline
\end{tabular}

S o u r c e : adapted from IGX, compiled by researcher. 